\title{
Biotechnology- Gene Transfer: Terminology, Techniques, and Problems Involved
}

\author{
Dennis A. Schaff ${ }^{1}$ \\ Delaware Agricultural Experiment Station, Department of Plant and Soil Sciences, College of Agricultural \\ Sciences, University of Delaware, Newark, DE 19717-1303
}

To most nonspecialists, the language and concepts of the molecular biology of gene transfer seem to be incomprehensible at worst and nebulous at best. The terminology and concepts will become more commonplace as the techniques of plant gene transfer become more routine. However, little of the terminology involved has been defined in ways that nonspecialists (both scientists and casual readers) can readily understand, and, therefore, the concepts remain confusing to these individuals. The goal here is to provide definitions of some of the common terms associated with these techniques and concepts so that the reader can better understand the concepts of biotechnology as they apply to plant molecular biology.

Biotechnology can be defined in broad terms as the use of biological agents, systems, or materials to produce goods or services for trade, industry, or commerce. Within this definition, biotechnology can be divided into four major areas: 1) bioprocessesfermentation for products such as wine, bread, and pharmaceuticals; 2) tissue culture-the culture of plants or plant parts in vitro for use in propagation, pathogen elimination, germplasm preservation, or for the induction and selection of useful variants; 3) immunologythe use of antibodies for the detection of plant disease-causing agents such as viruses; and 4) genetic engineering-the manipulation of plant DNA to alter the plant's characteristics. Although all of these areas are equally important, this paper will focus on the area of genetic engineering as it pertains to plant gene transfer (transgenic plants).

Genetic engineering of plants can be achieved by traditional plant breeding techniques and practices, or by recombinant DNA techniques. The aim of plant breeding is to develop new cultivars with enhanced or altered characteristics. Traditionally, new cultivars have been developed through the selection of progeny derived from sexual crosses (intraspecific and interspecific) between compatible species. Recently, the use of recombinant DNA technology and tissue culture for the production of transgenic plants has overcome the limitation of sexual compatibility. These techniques allow the transfer of genes from sexually and nonsexually compatible plants, as well as from other organisms (Goodman et al., 1987).

Published as Miscellaneous Paper no. 1324 of the Delaware Agricultural Experiment Station.

'Assistant Professor of Plant Molecular Biology.
Transgenic plants have the potential to increase our basic knowledge of plant genetics (Schell, 1987). Therefore, a basic understanding of the techniques and concepts involved in the production of transgenic plants is essential. This paper provides an overview of transgenic plant production and some aspects of molecular biology that relate to plant gene transfer.

\section{TERMINOLOGY}

\section{Genes, vectors, clones, and libraries}

A gene can be defined as a colinear piece of DNA that consists of a promoter (regulatory, 5' upstream sequences), coding regions (exons), noncoding regions (introns or intervening sequences), and a polyadenylation signal sequence ( 3 ' downstream sequences). The reason that this general definition has been chosen is that in eukaryotes, such as plants, introns are present and the messenger RNA (mRNA) is polyadenylated, whereas in prokalyotes, such as bacteria (i.e., Escherichia coli), introns are absent and the mRNA is not polyadenylated. These points might seem minor, but they become very important when the goal is expression of a plant gene in a bacterial system or of a bacterial gene in a plant system. The plant promoter and the introns must be removed and the coding region attached to a bacterial promoter to express a plant gene in a bacterial system. The coding region of the gene must be joined at the 5 ' end to a plant promoter and at the 3 ' end to a plant polyadenylation signal sequence for the expression of a bacterial or nonplant gene in a plant system (Fraley et al., 1983; Kuhlemeier et al., 1987; Rothstein et al., 1987; Schell, 1987). Most selectable markers and reporter genes in current use in plant gene transfer are of bacterial or nonplant origin (Fraley et al., 1983; Weising et al., 1988).

Cloning vectors are genetically engineered plasmids, viruses, or bacteriophages used to deliver and replicate foreign DNA in cells (usually bacteria). In general, these vectors contain a bacterial origin of replication, a selectable marker (i.e., an antibiotic-resistant gene), and a scoreable marker so that the vector can be selected and manipulated in bacteria. The widely used pUC vectors have an origin of replication for replication in bacteria, an ampicillin-resistant gene for selection of bacteria that have been transformed, and a lacZ 
gene for a scoreable marker (Yanisch-Perron et al., 198.5). The lacZ gene has been engineered to possess a region of DNA that contains several unique restriction enzyme recognition sequences. The lacZ gene product becomes nonfunctional when foreign DNA is inserted into this region. This phenomenon allows for the identification and selection of recombinant (vector DNA plus plant DNA) from the nonrecombinant vectors.

To manipulate genes using molecular techniques, a clone of the gene is needed. A clone is a collection of identical DNA molecules derived from a single ancestral DNA molecule. Cloning vectors that allow for the selection and propagation of recombinant DNA clones (plant DNA plus vector) in bacteria are available commercially. Clones can be either genomic DNA or complementary DNA (cDNA) that are isolated from genomic or cDNA libraries. A genomic library is a collection of recombinant DNA molecules that, together, carry the sequences representative of a species genome. The cDNA library is also a collection of recombinant DNA molecules, but represents only a population of expressed genes (transcribed mRNA). Therefore, many different cDNA libraries can be produced from the same plant using different plant parts (root, leaf, flower, etc.).

\section{Transgenic plants}

The mid- to late 1980s have been a time of significant advances in the production of transgenic plants. These advances have been due, in part, to the development of efficient gene vector systems and techniques of plant transformation and regeneration (Cocking and Davey, 1987; Gasser and Fraley, 1989; Klee et al., 1987; Kuhlemeier et al., 1987; Weising et al., 1988; Weissbach and Weissbach, 1987; Zaitlin and Hull, 1987). Production of transgenic plants, as a result of these advances, has been perceived as a possible approach for the control of farm pests, weeds, insects, and plant diseases (U.S. Congress, 1988). Transgenic plants have been produced to integrate new traits from other plants or organisms into target plants. For example, traits for resistance to herbicides, insects, and viruses have been transferred into plants (Gasser and Fraley, 1989; Nelson et al., 1988; Schell, 1987; Weising et al., 1988).

Transgenic plants are also used to study the DNA sequences essential for the control of gene expression within plants (Schell, 1987; Weising et al., 1988). This control can be general or specific. In certain transgenic plants, gene expression can be manipulated generally to increase the amount of a gene product, or manipulated specifically to: 1) express the gene product at unique stages of plant development or to 2) express the gene in organs where the gene product is not normally expressed (Hoffman et al., 1987; Smigocki and Owens, 1988). Transgenic plants have also been used to limit the expression of genes (van der Krol et al., 1988a). To accomplish this end, the gene to be limited is incorporated into the plant in the reverse orientation with respect to the promoter. The transferred gene produces antisense RNA that binds to the mRNA produced from the endogenous gene. Antisense RNA has been used to lower production of polygalacturonase in tomatoes (Sheehy et al, 1988; Smith et al., 1988) and chalcone synthase in petunia (van der Krol et al., 1988a, 1988b).

The most important step in developing transgenic plants is to determine which gene (trait) to transfer. This will be different for each project, depending on the goals of the project and the knowledge of the genetics controlling the trait. Once the goals are known and a gene of interest has been identified, the gene must be cloned. What is known about the gene will determine which techniques are used to isolate a clone (genomic or cDNA) of the gene.

\section{TECHNIQUES}

\section{Cloning/library construction}

Construction of a genomic library begins with the isolation of plant DNA. This DNA is digested with a restriction enzyme that cleaves at specific sequences positioned randomly throughout the plant DNA (genome). A cloning vector is digested with the same restriction enzyme or with a restriction enzyme that will produce compatible or "sticky" ends. The plant DNA fragments to be cloned and the vector DNA are ligated (bonded) together with DNA ligase to form recombinant DNA molecules. These molecules are subsequently used to transform competent $E$. coli cells. After the transformation procedure, the bacterial cells are plated on a selective medium containing an antibiotic that allows only bacteria transformed with the vector DNA to grow. Bacteria that have been transformed with the recombinant DNA molecules can then be selected. Each of the transformed bacterial colonies that contain a recombinant plasmid will have a clone of a portion of the plant genome. All the clones together comprise the genomic library.

A cDNA library is different from a genomic library in that it is a collection of mRNAs from currently expressed genes that do not contain promoter and intron sequences. The construction of cDNA libraries was made possible with the discovery of the enzyme reverse transcriptase in RNA viruses (Verma, 1977). The function of reverse transcriptase is to copy RNA into DNA. In short, a cDNA library is constructed by isolating total RNA from the plant part that is expressing the genes of interest. The mRNA that is polyadenylated at its $3^{\prime}$ end (poly- $\mathrm{A}^{+} \mathrm{RNA}$ ) is then separated from the total RNA (ribosomal, transfer, and mRNA) on an oligo-dT column. These mRNAs are converted into cDNA with reverse transcriptase. Each cDNA molecule is then ligated into a cloning vector and is used to transform competent $E$. coli. The transformed bacteria are subsequently selected. All of the clones together make up the cDNA library. Techniques for producing genomic and cDNA libraries are described in great detail in the manuals listed in Table 1. Currently, there are commercial sources for the production of both genomic and cDNA libraries.

\section{Gene transfer methods}

There are many methods that have potential for the production of transgenic plants. Currently, the most widely used method for the production of transgenic plants is the Agrobacterium- mediated gene transfer system (Cramer and Radin, 1990; Klee et al., 1987; Kuhlemeier et al., 1987; Weising et al., 1988; Zambryski, 1988). This procedure is considered to be a nondirect method of gene transfer because the gene must first be transferred into Agrobacterium. Other methods that have produced transgenic plants and have generally been classified as direct gene transfer include chemical treatment, electroporation, microinjection, and microprojectile bombardment (Fraley et al., 1986; Klein et al., 1988; McCabe et

Table 1. Laboratory manuals and videocassettes for molecular biology techniques.

Current Protocols in Molecular Biology

Ausubel et al., 1987

Gene Cloning and Analysis: A Laboratory Guide Boulnois, 1987

Methods in Plant Molecular Biology Schuler and Zielinski, 1989

Methods in Enzymology: Plant Molecular Biology. vol. 118 Weissbach and Weissbach, 1986

Methods in Enzymology. Guide to Molecular Cloning Techniques. vol. 152 Berger and Kimmel, 1987

Molecular Biology of Plants: A Text Manual Cherry, 1973

Molecular Cloning: A Laboratory Manual. 2nd ed. Sambrook et al., 1989

Molecular Biology of Plants. Cold Spring Harbor Laboratory Summer Course, 8-28 June 1984

Malmberg et al., 1985

Plant Molecular Biology Manual Gelvin et al., 1989

Plant Genetic Transformation and Gene Expression. A Laboratory Manual Draper et al., 1988

A Practical Guide to Molecular Cloning Perbal, 1984

The Techniques in Genetic Engineering Video Library Brown et al., 1984 
al., 1988; Potrykus, 1988; Saunders et al., 1989; Weising et al., 1988). Once a gene transfer method is chosen, the gene must be cloned into an appropriate vector. In general, these vectors should contain a bacterial origin of replication and a bacterial selectable marker so that the vector can be manipulated in bacteria. The vector should also contain a plant selectable marker to allow selection of transgenic plants, and a multiple cloning site. This multiple cloning site can be a region of DNA that contains unique restriction enzyme recognition sequences, or restriction enzyme sites flanked by a plant promoter (5' sequences) and a plant polyadenylation signal sequence ( 3 ' sequences). Vectors with these characteristics are available commercially.

Agrobacterium-mediated gene transfer. The plant pathogen Agrobacterium tumefaciens is a natural genetic engineer. Upon infection of a host plant, Agrobacterium transfers its T-DNA into the plant, which is stably integrated into the chromosome of the plant (Rogers et al., 1986; Schell, 1987; Weising et al,, 1987; Zambryski, 1988). The DNA transferred and integrated into the plant by the Agrobacterium is very precise; only the DNA that lies between the T-DNA borders is transferred and integrated in the plant genome. Usually one T-DNA copy is integrated per plant cell (Zambryski, 1988).

Direct gene transfer. Transgenic plants have been produced by the techniques of chemical treatment [calcium-phosphate and polyethylene glycol (PEG)], electroporation, microinjection, and microprojectile bombardment. These techniques deliver the foreign DNA directly into the plant cell. For both chemical treatment and electroporation, the cells to be transformed are first converted into protoplasts by the removal of their cell walls. For chemical treatment, protoplasts are incubated with DNA and calcium phosphate or PEG to facilitate DNA uptake into the cell (Fraley et al., 1986; Potrykus, 1988; Weising et al., 1988). Electroporation of plant protoplasts or germinating pollen requires that cells be exposed to a high-voltage electrical charge for a short time. Cell membranes develop large pores through which DNA moves during the electrical charge and can be incorporated into the plant genome (Fraley et al., 1986; Saunders et al., 1989; Weising et al., 1988). Microinjection is achieved by placing a small needle into the cell and injecting DNA directly into the nucleus (Fraley et al., 1986; Potrykus, 1988). Microprojectile bombardment is a method that can be performed on an intact plant. The plant is subjected to a shower of high-velocity particles that are coated with DNA (Klein et al., 1988; McCabe et al., 1988; Schell, 1987). All of these techniques have their limitations. The method of transformation selected will depend on the species and characteristics of the plant to be transformed.

\section{Isolation of transgenic plants}

Regardless of the technique used, a mixture of both transformed and nontransformed plant tissue is present following the transformation process. This mixture of tissue can be sorted out by using a plant selectable marker or by using reporter enzyme systems (Rogers et al., 1987; Rothstein et al., 1987; Schell, 1987; Weising et al., 1988). Most of the techniques rely on selectable markers that will allow only tissue that is transformed to grow on selective media. The most widely used selectable marker for plants is the neomycin phosphotransferase II ( kan ) gene, which confers resistance to kanamycin. Only transformed plants that have incorporated the kan gene should grow on media that contains kanamycin. Also, the level of expression of the kan gene can be determined. Another plant selectable marker in use is the hygromycin phosphotransferase gene ( $h p t$ ), which confers resistance to hygromycin B (Rothstein et al., 1987). Some widely used reporter enzyme systems in plants are: chloramphenicol acetyltransferase (CAT); ß-glucuronidase (GUS); and luciferase (Jefferson et al., 1987; Ow et al., 1986; Schell, 1987; Weising et al., 1988).

\section{Verification of transgenic plants}

Southern blot analysis. Growth of transformed plant tissue on selective medium is not conclusive evidence for successful production of transgenic plants. The use of Southern blot analysis will verify the identification of transgenic plants. A positive Southern blot analysis ensures that the transgenic plant has the DNA of interest incorporated into its genome. Southern blot analysis begins by extracting the genomic DNA from the plant. The genomic DNA is either undigested or digested with a restriction enzyme and subjected to gel electrophoresis to separate the DNA by size. Then, the size-fractionated DNA is immobilized on nitrocellulose by blotting. The DNA on the nitrocellulose blot is hybridized with a radioactively labeled DNA probe that is prepared from a sample of the DNA (gene) used in the construction of the transgenic plant. The results are visualized by autoradiography. A Southern blot with undigested DNA will show whether the transferred DNA has been incorporated into the genome of the plant or whether it remains as an extrachromosomal element. The extrachromosomal location of the DNA may be due to contamination, because the transferred DNA should not contain a plant origin of replication. A positive Southern blot with restriction-enzyme-digested DNA will allow the estimation of the number of insertion sites where the transferred DNA has been incorporated into the plant's genome.

Northern blot analysis. Plants with "positive" Southern blots are transgenic. However, sometimes these transgenic plants do not produce the trait that the transferred gene confers. One cause may be that the transferred gene is not being transcribed in the plant or tissue of interest. This can be tested with a northern blot. The northern blot is similar to the Southern blot; however, the Southern blot evaluates DNA incorporation, while the northern blot evaluates mRNA production (gene expression). A positive result with the northern blot verifies that the transferred gene is being transcribed into mRNA.

Western blot analysis. A western blot is similar to the Southern and northern blots. However, while the Southern and northern blots evaluate DNA and RNA, respectively, and require a nucleic acid probe, the western blot evaluates proteins and requires an antibody against the protein of interest. Western blots and specific enzyme activity assays are used to evaluate the production of gene products (protein) in transgenic plants. The amount of gene product can be estimated from the results of an activity assay or western blot.

Evaluation. Transgenic plants may have one or more copies of the gene incorporated, depending on the method of gene transfer (Schell, 1987; Weising et al., 1988; Zambryski, 1988). The transgenic nature of the plants is verified, then they are evaluated in greenhouse and field tests for inheritance, stability, and breeding behavior of the trait.

\section{PROBLEMS INVOLVED}

Advances in plant gene transfer and in production of transgenic plants have occurred very rapidly over the past 5 years. These advances have made it possible to introduce DNA into plants for the production of new traits, such as resistance to herbicides, insects, or viruses and for the study of plant genes and their controlling elements (Cramer and Radin, 1990; Fraley et al., 1983; Gasser and Fraley, 1989; Goodman et al., 1987; Kuhlemeier et al., 1987; Schell, 1987; van der Krol et al., 1988a, 1988b; Weinand and Saedler, 1987; Weising et al., 1988; Zaitlin and Hull, 1987). However, both technical and nontechnical limitations still exist.

The technical limitations for gene transfer in plants include a lack of basic knowledge about transformation and regeneration of most plants. These limitations are being addressed by the development of a better understanding of the mechanisms of Agrobacterium host specificity and T-DNA transfer (Zambryski, 1988). To overcome problems of plant regeneration, the use of microprojectile bombardment of plant meristems and electroporation of pollen are being investigated. These procedures bypass the regeneration step by directly transforming tissue that will give rise to the next generation and thereby pass on the transferred gene.

The expression of genes in transgenic plants may not be as anticipated. The gene transferred may be expressed in an unexpected tissue or stage of development or at a level too low to be effective. These unwanted results could be related to the genotype of the transformed plant or the promoter of the gene.

Nontechnical issues can be at least as restrictive as the technical limitations for the production and use of transgenic plants (Gasser 
and Fraley, 1989; Tolin and Vidaver, 1989). These issues include public perception and regulatory approval of the procedures. Without satisfying all of these constituents, the use of transgenic plants will be hindered.

\section{Literature Cited}

Ausubel, F.M., R. Brent, R.E. Kingston, D.D. Moore, J.G. Seidman, J.A. Smith, and K. Struhl. 1987. Current protocols in molecular biology. Wiley, New York.

Berger, S.L. and A.R. Kimmel. 1987. Methods in enzymology. Guide to molecular cloning techniques. vol. 152. Academic, New York.

Boulnois, G.J. 1987. Gene cloning and analysis: A laboratory guide. Blackwell Scientific Publications, Oxford, U.K.

Brown, S.D.M., R. Williamson, K.E. Davies, T.J.R. Harris, A.D.B. Malcolm, and A. Wilkinson. 1984. The techniques in genetic engineering video library. IRL Press Video, Arlington, Va.

Cherry, J.H. 1973. Molecular biology of plants; A text manual. Columbia University Press, New York.

Cocking, E.C. and M.R. Davey. 1987. Gene transfer in cereals. Science 236:1259-1262.

Cramer, C.L. and D.N. Radin. 1990. Molecular biology of plants, p. 149. In: J.P. Nakas and C. Hagedorn (eds.). Biotechnology of plantmicrobe interactions. McGraw Hill, New York.

Draper, J., R. Scott, P. Armitage, and R. Walden. 1988. Plant genetic transformation and gene expression. A laboratory manual. Blackwell Scientific Publications, Oxford, U.K.

Fraley, R.T., S.G. Rogers, and R.B. Horsch. 1986. Genetic transformation in higher plants. CRC Critical Rev. Plant Sci. 4:1-46.

Fraley, R.T., S.G. Rogers, R.B. Horsch, P.R. Sanders, J.S. Flick, S.P. Adams, M.L. Bittner, L.A. Brand, C.L. Fink, J.S. Fry, G.R. Galluppi, S.B. Goldberg, N.L. Hoffmann, and S.C. Woo. 1983. Expression-of bacterial genes in plants. Proc. Natl. Acad. Sci. USA 80:4803-4807.

Gasser, C.S. and R.T. Fraley. 1989. Genetically engineering plants for crop improvement. Science 244:1293-1299.

Gelvin, S.B., R.A. Schilperoort, and D.P.S. Verma. 1989. Plant molecular biology manual. Kluwer Academic Publisher, Boston.

Goodman, R.M., H. Hauptli, A. Crossway, and V.C. Knauf. 1987. Gene transfer in crop improvement. Science 236:48-54.

Hoffman, L.M., D.D. Donaldson, R. Bookland, K. Rashka, and E.M. Herman. 1987. Synthesis and protein body deposition of maize $15-\mathrm{kb}$ zein in transgenic tobacco seeds. EMBO J. 6:3213-3221.

Jefferson, R.A., T.A. Kavanagh, and M.W. Bevan. 1987. GUS fusions: B-glucuronidase as a sensitive and versatile gene fusion marker in higher plants. EMBO J. 6(13):3901-3907.

Klee, H.J., R. Horsch, and S. Rogers. 1987. Agrobacterium-mediated plant transformation and its further applications to plant biology. Annu. Rev. Plant Physiol. 38:467-486.

Klein, T.M., T. Gradziel, M.E. Fromm, and J.C. Sanford. 1988. Factors influencing gene delivery into Zea mays cells by high-velocity microprojectiles. Bio/Technology 6:559-563.

Kuhlemeier, C., P.J. Green, and N.-H. Chua. 1987. Regulation of gene expression in higher plants: Annu. Rev. Plant Physiol. 38:221-257.

Malmberg, R., J.W. Messing, and I.M. Sussex. 1985. Molecular biology of plants. Cold Spring Harbor Laboratory Summer Course, 8-28 June 1984. Cold Spring Harbor Lab., Cold Spring Harbor, N.Y.

McCabe, D.E., W.F. Swain, B.J. Martinell, and P. Christou. 1988. Stable transformation of soybean (Glycine max) by particle acceleration. Bio/Technology 6:923-926.

Nelson, R.S., S.M. McCormic, X. Delannay, P. Dubé J. Layton, E.J. Anderson, M. Kaniewska, R.K. Proksch, R.B. Horsch, S.G. Rogers, R.T. Fraley, and R.N. Beachy. 1988. Virus tolerance, plant growth, and field performance of transgenic tomato plants expressing coat protein from tobacco mosaic virus. Bio/Technology 6:403-409.

Ow, D.W., K.V. Wood, M. DeLuca, J.R. de Wet, D.R. Helinski, and S.H. Howell. 1986. Transient and stable expression of the firefly lucif- erase gene in plant cells and transgenic plants. Science 234:856-859.

Perbal, B.V. 1984. A practical guide to molecular cloning. Wiley, New York.

Potrykus, I. 1988. Direct gene transfer to plants, p. 144-162. In: G. Bock and J. Marsh (eds.). Applications of plant cell and tissue culture. Wiley, Chichester. Sussex. U.K. (Ciba Foundation Symp. 137.)

Rogers, S.R. R.B. Horsch, and R.T. Fraley. 1986. Gene transfer in plants: Production of transformed plants using Ti plasmid vectors. Methods in Enzymology 118:627-640.

Rogers, S.G., H. Klee, R.B. Horsch, and R.T. Fraley. 1987. Improved vectors for plant transformation: Expression cassette vectors and new selectable markers. Methods in Enzymology 153:253-277.

Rothstein, S.J., K.N. Lahners, R.J. Lotstein, N.B. Carozzi, S.M. Jayne, and D.A. Rice. 1987. Promoter cassettes, antibiotic-resistance genes, and vectors for plant transformation. Gene 53:153-161.

Sambrook, J., E.F. Fitsch, and T. Maniatis. 1989. Molecular cloning: A labortory manual. 2nd ed. Cold Spring Harbor Lab., Cold Spring Harbor, N.Y.

Saunders, J.A., B.F. Matthews, and P.D. Miller. 1989. Plant gene transfer using electrofusion and electroporation, p. 343-354. In: E. Neumann, A.E, Sowers, and C.A. Jordan (eds.). Electroporation and electrofusion in cell biology. Plenum Publishing, New York.

Schell, J. 1987. Transgenic plants as tools to study the molecular organization of plant genes. Science 237:1176-1182.

Schuler, M.A. and R.E. Zielinski. 1989. Methods in plant molecular biology. Academic, New York.

Sheehy, R.E., M. Kramer, and W.R. Hiatt. 1988. Reduction in polygalacturonase activity in tomato fruit by antisense RNA. Proc. Natl. Acad. Sci. USA 85:8805-8809.

Smigocki, A.C. and L.D. Owens. 1988. Cytokinin gene fused with a strong promoter enhances shoot organogenesis and zeatin levels in transformed plant cells. Proc. Natl. Acad. Sci. USA 85:5131-5135.

Smith, C.J.S., C.F. Watson, J. Ray, C.R. Bird, P.C. Morris, W. Schuch, and D. Grierson. 1988. Antisense RNA inhibition of polygalacturonase gene expression in transgenic tomatoes. Nature 334:724-726.

Tolin, S.A. and A.K. Vidaver. 1989. Guidelines and regulations for research with genetically modified organisms: A view from academe. Annu. Rev. Phytopathol. 27:551-581.

U.S. Congress, Office of Technology Assessment. 1988. New developments inbiotechnology-Field testing engineered organisms: Genetic and ecological issues. OTA-BA-350. May 1988. U.S. Government Printing Office, Washington, D.C.

van der Krol, A.R., P.E. Lenting, J. Veenstra, I.M. van der Meer, R.E. Koes, A.G.M. Gerats, J.N.M. Mol, and A.R. Stuitje. 1988a. An antisense chalcone synthase gene in transgenic plants inhibits flower pigmentation. Nature 333:866-869.

van der Krol, A.R., J.N.M. Mol, and A.R. Stuitje. 1988b. Modulation of eukaryotic gene expression by complementary RNA or DNA sequences. BioTechniques 6(10):958-976.

Verma, I.M. 1977. Reverse transcriptase, p. 87-104. In: P.D. Boyer (ed.). The enzymes, vol. 14A. Academic, New York.

Weinand, U. and H. Saedler. 1987. Plant transposable elements: Unique structures for gene/transposable tagging and gene cloning. Plant Gene Res. 4:205-227.

Weising, K., J. Schell, and G. Kahl. 1988. Foreign genes in plants: Transfer, structure, expressions, and applications. Annu. Rev. Genet. 22:421477 .

Weissbach, A. and H. Weissbach. 1986. Methods in enzymology: Plant molecular biology. vol. 118. Academic, New York.

Yanisch-Perron, C., J. Vieria, and J. Messing. 1985. Improved M13 phage cloning vectors and host strains: Nucleotide sequences of the M13mp18 and pUC19 vectors. Gene 33:103-119.

Zaitlin. M. and R. Hull. 1987. Plant virus-host interactions. Annu. Rev. Plant Physiol. 38:291-315.

Zambryski, P. 1988. Basic processes underlying Agrobacterium-mediated DNA transfer to plant cells. Annu. Rev. Genet. 22:1-30. 